\title{
Influence of Wheelchair Cushions Fabricated by Therapists on Stability, Comfort, and Functionality
}

\author{
Takeshi Oshikawa1 ${ }^{*}$, Seigo Koura1 ${ }^{1}$, Nishikawa Chihoko² ${ }^{2}$ Kazuho Nagao ${ }^{2}$, Kentaro Higashi \\ ${ }^{1}$ Department of Rehabilitation, Nishikyusyu University, Saga, Japan \\ ${ }^{2}$ Social Welfare Corporation, Kanjikai, Japan \\ Email: *oshikawata@nisikyu-u.ac.jp
}

How to cite this paper: Oshikawa, T., Koura, S., Chihoko, N., Nagao, K. and Higashi, K. (2020) Influence of Wheelchair Cushions Fabricated by Therapists on Stability, Comfort, and Functionality. Open Journal of Therapy and Rehabilitation, 8, 1-11. https://doi.org/10.4236/ojtr.2020.81001

Received: December 16, 2019

Accepted: February 25, 2020

Published: February 28, 2020

Copyright $\odot 2020$ by author(s) and Scientific Research Publishing Inc. This work is licensed under the Creative Commons Attribution International License (CC BY 4.0).

http://creativecommons.org/licenses/by/4.0/

\begin{abstract}
"Ease of comfort" and "functionality" are important factors that have been cited to improve wheelchair seating. The ability to maintain balance and posture while seated in a wheelchair improves stability, comfort, and functionality and is a prerequisite for daily activities. In this study, the authors used a sitting position measuring device to scientifically verify differences in sitting posture, comfort, and functionality depending on the presence or absence of cushions and the type of cushion in elderly individuals who used wheelchairs. Results suggested that a cushion fabricated by a therapist was more useful than a commercially available air cushion. While a commercially available air cushion was the most suitable, the therapist's self-made cushion could be expected to demonstrate the same or better applicability than an air cushion.
\end{abstract}

\section{Keywords}

Wheelchair Sitting, Stability, Cushion, Comfort, Functionality

\section{Introduction}

Wheelchair seating is a generic term that refers to devices such as wheelchairs [1] [2] [3] [4] and cushion devices [5]-[10] and their proper use and management. The purpose of wheelchair seating is "comfort", "functionality", "physiological mobility", "practicality" and "appearance" [11]. Collins [12] reported that the ultimate goal of cushion use, which is important for wheelchair seating, is stability, comfort, and functionality. The ability to maintain balance and posture while sitting in a wheelchair improves stability, comfort, and functionality and is 
a prerequisite for the activities of daily living [13] [14].

Measuring the stability of an individual in a wheelchair depends on the researcher and the evaluation method. However, in recent years, devices used to measure sitting pressure have begun to be used as a method to quantify the stability of the sitting position. Previous studies have used sit pressure measuring devices to assess wheelchair differences [15], pelvic limb position differences [16], and foot support height/seat surface height differences [17].

Although studies investigating wheelchair cushions have been conducted in healthy individuals [18], they have not been verified in elderly individuals who use wheelchairs. It has been reported that the elderly exhibit a significant decline in mental and physical functioning due to aging, and it is difficult to recover this function once it has declined [19].

The purpose of the present study was to scientifically verify differences in comfort and functionality depending on the presence or absence of cushions, and the type of cushions for elderly individuals who use a wheelchair. The results are anticipated to facilitate approaches to interventions for wheelchair seating by therapists.

\section{Subjects and Methods}

\subsection{Subjects}

Subjects included 10 people who were wheelchair-user for orthopedic disease and recruited randomly from nursing homes. The subjects consisted of two men and eight women with an average age of $91.7 \pm 9.4$ years and an average weight of $49.1 \pm 7.5 \mathrm{~kg}$. who used a wheelchair due to orthopedic disease(s) and were recruited from nursing homes and day service centers and met the following criteria: used a wheelchair in daily life; absence of pressure ulcer(s) for at least one year; no orthopedic problems that could interfere with the ability to perform specific tasks while sitting; and the ability to sit continuously for $60 \mathrm{~min}$. All subjects were right-handed, and all procedures were approved by the Nishikyushu University (Saga, Japan) Ethics Committee (H30-15).

\subsection{Methods}

\subsubsection{Wheelchairs and Wheelchair Cushions}

A survey method was used to examine two factors-comfort and functionality-depending on the presence and type of cushion. The wheelchair was a simple modular wheelchair (Miki. Co. Ltd., Tokyo, Japan) rented by the facility. Modular wheelchairs have adjustable foot support, back support and arm support. Wheelchair cushions were flat-type adult cushions (5TC-045, Takano Heart Works, Inc., Nagoya, Japan), hereinafter referred to as the "F-cushion" and air cushions (Solostolators, Tuki Trading, Inc.), hereinafter referred to as the "A-cushion", and cushions fabricated by the therapist (self-made). The primary characteristic of the F-cushion was that its main material was urethane, which is inexpensive and easy to obtain but lacks durability and must be replaced every year [18]. A-cushions can effectively distribute pressure by adjusting the air pressure; how- 
ever, they are expensive and require regular air pressure adjustment [20]. The self-made cushion could reproduce an effective pressure-dispersed buttock shape obtained using the A-cushion with urethane material and adds a net-like cushion in consideration of air permeability.

\subsubsection{Equipment and Scales}

1) Sitting Position Measuring Device: $X-S E N S O R$ (Calgary, AB, Canada)

Data collected using the X-SENSOR device are outputted as the pressure value of each element. Measurements of the bearing surface contact area and center-of-gravity movement were also possible. In this study, two-dimensional data were obtained at a rate of 20 frames/s. Data regarding the contact area of each subject's seat was expressed as the average value over a 10-min period. The center-of-gravity movement was determined by taking the center-of-gravity position of the reference point of each subject as the average value for $5 \mathrm{~s}$ after sitting and defining the distance moved from the reference point $(\mathrm{mm})$ as the distance of center-of-gravity movement. Data believed to be collected during unexpected movement(s) were excluded (Figure 1).

2) Subjective Satisfaction: Visual Analog Scale of Happiness [21]

The visual analog scale of happiness (VAS-H) was used to evaluate comfort. The VAS-H investigated 3 items in a 10-min period of continuous sitting and scored from 0 (worst discomfort) to 10 (maximum comfort). At the same time, changes in the contact area and center-of-gravity movement according to the X-SENSOR seat pressure measuring device for a 10 -min period were investigated. Postural evaluation was performed after $10 \mathrm{~min}$ of continuous sitting.

3) Sitting Posture Measuring Instrument

Posture comfort was evaluated with subjects in the sitting position for $10 \mathrm{~min}$ to obtain the pelvic inclination angle and the seat surface position (distance from the seat tip). The pelvic inclination angle was measured using a commercially available device (Horizon, Tuki Trading). The Horizon device can measure various objects and body tilt angles in three dimensions (Figure 2) [22].

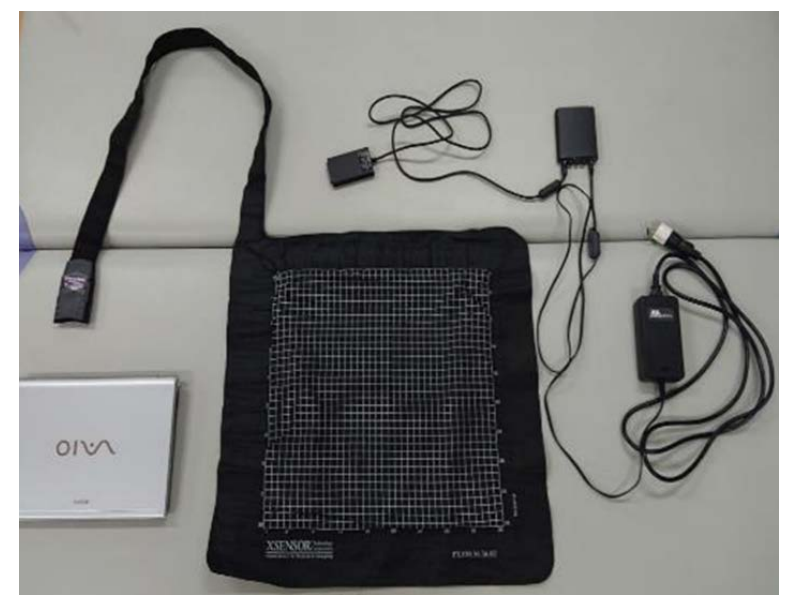

Figure 1. Sitting position measuring device "X-SENSOR (Calgary, AB, Canada)" X-SENSOR was used to Measurements of surface contact area and center-of-gravity movement. 


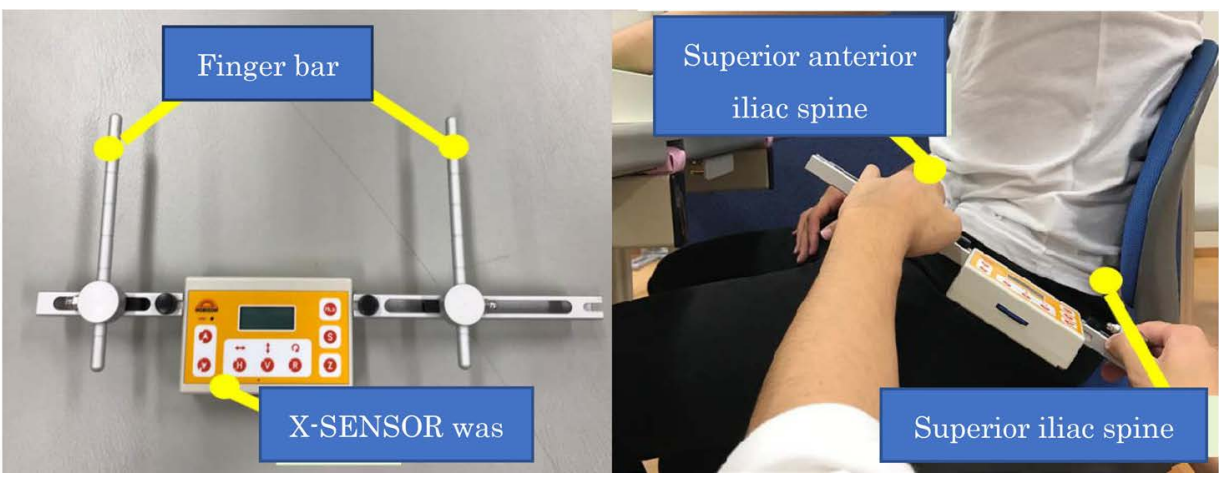

Figure 2. Sitting posture measuring instrument "Horizon". The figure on the right shows a measurement of the pelvic posterior tilt angle.

4) Sit and Reach Test

The sit and reach test (SRT) [23] is a posture balance test using the upper limb forward reach motion in the sitting position. The wheelchairs were adjusted according to the body dimensions of each subject so that the subject's posture was the sitting position (hereinafter referred to as the basic limb position) set to the 90 degree rule posture [24] according to the Ministry of Health, Labor, and Welfare. The upper limb from the basic limb was lifted 90 degrees in the elbow extension position and moved as far forward as possible. At this time, the movement distance to the maximum reach position, with the buttocks not separated from the seating surface, was measured. In this examination, in addition to forward reach, side reach was also assessed, which was clinically useful.

\subsubsection{Stability Evaluation}

Stability was evaluated by adjusting the wheelchair to the basic limb position. The X-SENSOR was then used to survey the "contact area" between the cushion and the buttocks during 10 min of continuous sitting and the SRT for each subject. The contact area data for the continuous sitting position were compared with the average value, and the contact area data for the SRT were compared with the maximum and minimum values.

\subsubsection{Comfort Evaluation}

VAS-H was used for the subjective "sitting comfort" evaluation of comfort, and the pelvic tilt angle and the seat surface positions (distance from the seat tip) were used for the "posture change due to pain". The measurement time was 10 minutes and compared before and after continuous sitting. The VAS-H was used to evaluate comfort by assessing 3 items continuous sitting position, with worst discomfort scored as 0 and maximum comfort scored as 10. Based on ISO16840-125 [25], the pelvic inclination angle was measured from the basic limb position (pelvic inclination angle, 0 degrees), with the upper anterior iliac spine and the upper posterior iliac spine as landmarks. The seat surface position was measured by measuring the distance from the basic limb position to the front and using a ruler from the tip of the wheelchair seat to the buttocks (Figure 3). 

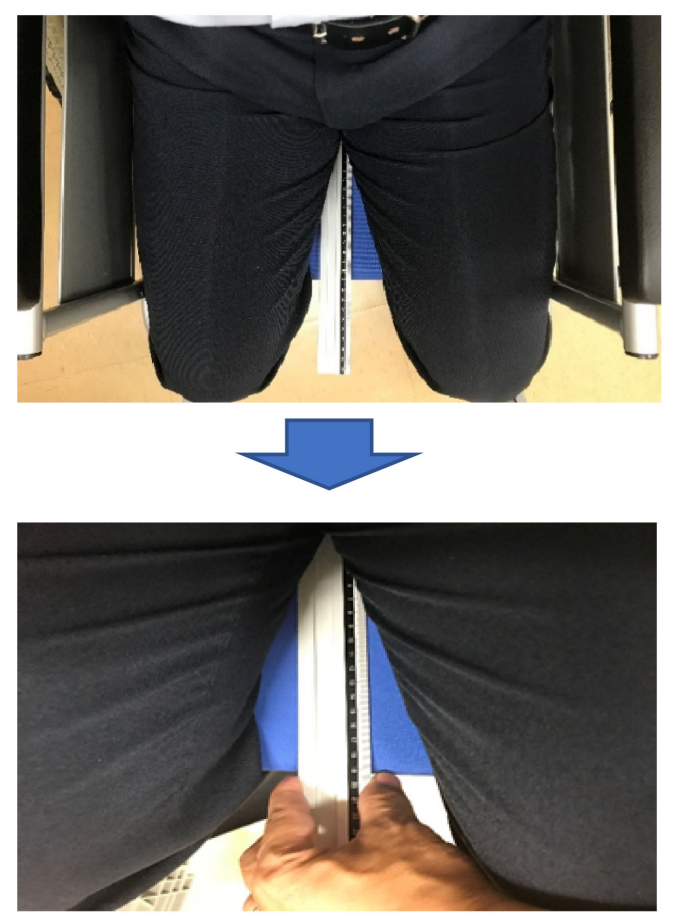

Figure 3. Seat surface position (distance from the seat tip to the buttocks). This was performed to measure the displacement of the buttocks. The straightedge ruler was used for measurement.

\subsubsection{Evaluation of Functionality}

Changes from the basic limb position were measured using the SRT, and the center-of-gravity movement was measured using the X-SENSOR. The center position, that is, the reference point for center-of-gravity movement, was the average value over a 5-s period after sitting, and the maximum movement distance $(\mathrm{cm})$ from this reference point was defined as the distance of center-of-gravity movement.

\subsubsection{Statistical Analysis}

Data regarding sitting position, comfort, SRT, and X-SENSOR were compared using one-way analysis of variance and multiple comparison test (Tukey test). SPSS version 20 (IBM Corporation, Armonk, NY, USA) for Windows (Microsoft Corporation, Redmond, WA, USA) was used for statistical analysis. Data are expressed as mean $\pm \mathrm{SD}$.

\section{Results}

Based on the results of one-way analysis of variance of the comparison results of the presence or absence of cushions and of stability, comfort, and functionality depending on the type of cushion, the null hypothesis (the population mean of each of the three groups is equal) was rejected and the alternative hypothesis (the population mean of the group mean of at least one group is different) was adopted. Based on this result, a multiple comparison test was performed.

Results of the comparison of stability, the presence/absence of cushion, con- 
tinuous sitting position according to the type of cushion, and the contact area during SRT measurement are summarized in Table 1. From these data, a significant difference was evident with and without cushion for both continuous sitting and SRT measurements; however, no significant difference was observed between the cushions. For comparison of comfort after continuous sitting, VAS-H, pelvic tilt angle, and distance from seat tip were measured. The results are shown in Table 2. The VAS-H scores were significantly higher in the cushioned group, and neither the pelvic tilt angle nor the distance from the seat tip demonstrated significant changes in sitting posture. For the comparison of functionality, the reach range of functionality and the movement of the center of gravity were measured; the results are presented in Table 3. The functional reach range was significantly different in the A-cushion and self-made cushion groups in all three directions, although the center-of-gravity shift was not significantly different in the comparisons.

\section{Discussion}

In this study, we examined the relationship between seating area and cushion

Table 1. Comparison of stability.

\begin{tabular}{|c|c|c|c|c|c|}
\hline Item & $\begin{array}{l}\text { I. Without cushion } \\
\text { non-intervention }\end{array}$ & $\begin{array}{l}\text { II. F cushion } \\
\text { intervention }\end{array}$ & $\begin{array}{l}\text { III. A cushion } \\
\text { intervention }\end{array}$ & $\begin{array}{l}\text { IV. Self-made cushion } \\
\text { intervention }\end{array}$ & ANOVA \\
\hline During continuous sitting position measurement & & & & & $\mathrm{I}<\mathrm{II}^{*}$ \\
\hline $\begin{array}{l}\text { Bearing surface contact area } \\
\qquad\left(\mathrm{cm}^{2}\right) \mathrm{n}=10\end{array}$ & $1264.5 \pm 196.0$ & $1663.2 \pm 117.4$ & $1769.7 \pm 93.3$ & $1771.7 \pm 91.8$ & $\begin{array}{l}\mathrm{I}<\mathrm{III}^{*} \\
\mathrm{I}<\mathrm{IV}^{*}\end{array}$ \\
\hline $\begin{array}{l}\text { During SRT measurement } \\
\text { Maximum bearing surface contact area } \\
\left(\mathrm{cm}^{2}\right) \mathrm{n}=10\end{array}$ & $1393.9 \pm 218.7$ & $1736.0 \pm 109.4$ & $1845.0 \pm 76.8$ & $1855.3 \pm 75.3$ & $\begin{array}{l}\mathrm{I}<\mathrm{II}^{*} \\
\mathrm{I}<\mathrm{III}^{*} \\
\mathrm{I}<\mathrm{IV}^{*}\end{array}$ \\
\hline $\begin{array}{l}\text { During SRT measurement } \\
\text { Minimum seating surface contact area } \\
\left(\mathrm{cm}^{2}\right) \mathrm{n}=10\end{array}$ & $1210.8 \pm 200.2$ & $1586.9 \pm 106.8$ & $1704.8 \pm 82.6$ & $1783.3 \pm 79.7$ & $\begin{array}{l}\mathrm{I}<\mathrm{II}^{*} \\
\mathrm{I}<\mathrm{III}^{*} \\
\mathrm{I}<\mathrm{IV}^{*}\end{array}$ \\
\hline
\end{tabular}

Mean value \pm standard deviation; ${ }^{*} \mathrm{p}<0.05$; One-way analysis of variance, multiple comparison Tukey.

Table 2. Comparison of comfort.

\begin{tabular}{|c|c|c|c|c|c|}
\hline Item & $\begin{array}{l}\text { I. Without cushion } \\
\text { non-intervention }\end{array}$ & $\begin{array}{l}\text { II. F cushion } \\
\text { intervention }\end{array}$ & $\begin{array}{l}\text { III. A cushion } \\
\text { intervention }\end{array}$ & $\begin{array}{l}\text { IV. Self-made cushion } \\
\text { intervention }\end{array}$ & ANOVA \\
\hline $\begin{array}{c}\text { Comfortability: } \\
\text { VAS-H (point) } n=10\end{array}$ & $3.4 \pm 1.3$ & $7.4 \pm 0.4$ & $8.7 \pm 0.4$ & $9.2 \pm 0.6$ & $\begin{array}{l}\mathrm{I}<\mathrm{II}^{*} \\
\mathrm{I}<\mathrm{III}^{*} \\
\mathrm{I}<\mathrm{IV}^{*}\end{array}$ \\
\hline $\begin{array}{l}\text { Pelvic tilt angle (degrees): } \\
\text { Difference from } 90 \text { degrees } \\
\qquad \mathrm{n}=10\end{array}$ & $23.1 \pm 4.4$ & $16.9 \pm 2.4$ & $13.6 \pm 2.7$ & $13.4 \pm 2.3$ & $\begin{array}{l}\mathrm{I}<\mathrm{II}^{*} \\
\mathrm{I}<\mathrm{III}^{*} \\
\mathrm{I}<\mathrm{IV}^{*}\end{array}$ \\
\hline $\begin{array}{l}\text { Sitting position: } \\
\text { Distance from seat tip } \\
(\mathrm{cm}) \mathrm{n}=10\end{array}$ & $11.8 \pm 3.3$ & $17.1 \pm 1.5$ & $18.0 \pm 2.8$ & $18.14 \pm 2.7$ & $\begin{array}{l}\mathrm{I}<\mathrm{II}^{*} \\
\mathrm{I}<\mathrm{III}^{*}, \\
\mathrm{I}<\mathrm{IV}^{*}\end{array}$ \\
\hline
\end{tabular}

Mean value \pm standard deviation; ${ }^{*} \mathrm{p}<0.05$; One-way analysis of variance, multiple comparison Tukey. 
Table 3. Comparison of functionality.

\begin{tabular}{|c|c|c|c|c|c|}
\hline Item & $\begin{array}{l}\text { I. Without cushion } \\
\text { non-intervention }\end{array}$ & $\begin{array}{l}\text { II. F cushion } \\
\text { intervention }\end{array}$ & $\begin{array}{l}\text { III. A cushion } \\
\text { intervention }\end{array}$ & $\begin{array}{l}\text { IV. Self-made cushion } \\
\text { intervention }\end{array}$ & ANOVA \\
\hline $\begin{array}{c}\text { Functionality: } \\
\text { Reach range (front) } n=10\end{array}$ & $16.4 \pm 9.4$ & $24.0 \pm 7.9$ & $29.0 \pm 10.3$ & $29.5 \pm 9.4$ & $\begin{array}{l}\mathrm{I}<\mathrm{III}^{*} \\
\mathrm{I}<\mathrm{IV}^{*}\end{array}$ \\
\hline $\begin{array}{c}\text { Functionality: } \\
\text { Reach range (right) } n=10\end{array}$ & $8.0 \pm 4.0$ & $13.0 \pm 6.1$ & $15.4 \pm 6.0$ & $15.5 \pm 5.7$ & $\begin{array}{l}\mathrm{I}<\mathrm{III}^{* *}, \\
\mathrm{I}<\mathrm{IV}^{* *}\end{array}$ \\
\hline $\begin{array}{c}\text { Functionality: } \\
\text { Reach range (left) } n=10\end{array}$ & $7.8 \pm 3.5$ & $10.9 \pm 4.3$ & $14.3 \pm 4.9$ & $14.3 \pm 4.8$ & $\begin{array}{l}\mathrm{I}<\mathrm{III}^{*} \\
\mathrm{I}<\mathrm{IV}^{*}\end{array}$ \\
\hline $\begin{array}{l}\text { Measurement of functionality: } \\
\text { Back and forth center of gravity } \\
\text { movement } \\
(\mathrm{cm}) \mathrm{n}=10\end{array}$ & $3.1 \pm 1.6$ & $4.0 \pm 2.4$ & $3.9 \pm 1.9$ & $3.9 \pm 1.9$ & NS \\
\hline $\begin{array}{l}\text { Measurement of functionality: } \\
\text { Left and right center of } \\
\text { gravity movement } \\
(\mathrm{cm}) \mathrm{n}=10\end{array}$ & $1.8 \pm 1.7$ & $3.2 \pm 1.8$ & $2.7 \pm 1.4$ & $2.5 \pm 1.3$ & NS \\
\hline
\end{tabular}

Mean value \pm standard deviation; ${ }^{\star} \mathrm{p}<0.05,{ }^{* *} \mathrm{p}<0.01 ;$ NS: No significant difference; One-way analysis of variance, multiple comparison Tukey.

type (i.e., F-cushion, A-cushion, and self-made cushion) in wheelchair users according to sitting posture, comfort, and functionality. Results suggested that the A-cushion and self-made cushion benefitted sitting posture (pelvic tilt angle, distance from seat tip), comfort, and functionality in wheelchair users.

As a comparison of stability, a comparison of the presence or absence of cushions and of continuous sitting time for each type of cushion and the contact area at the time of SRT measurement revealed a significant difference in comparisons with and without cushion. There was no significant difference in continuous sitting time and contact area among the cushions. Bengt reported that "the cushion along the anatomical shape provides stability and equal pressure distribution to the pelvis and thighs" [26]. However, although there was a tendency for the contact area to be large, no clear correlation was observed. This is believed to be due to the small number of subjects. In addition, the F-cushion, made from urethane, cannot sufficiently reproduce the shape of the buttocks. However, it was suggested that a sufficient contact area of the seating surface may be obtained if the therapist attempts to suit the hardness of the material in a custom-made manner.

Regarding the comparison of comfort, the results of VAS-H, pelvic inclination angle, and distance from the tip of the seat after continuous sitting were significantly higher in the cushioned group, and there was little change in the sitting posture. This result suggests a correlation between stability and comfort.

Regarding the relationship between contact area and maximum contact pressure, Ito reported that "an increase in the contact area leads to a decrease in the maximum contact pressure" [27]. Assuming this, with cushioning, the increase 
in contact area decreases the contact pressure and enhances the VAS-H score, which is an index of subjective satisfaction and is used as an index of posture change to avoid pain. The angle, inclination angle, and the distance from the seat tip demonstrated little change from the basic limb position.

Regarding the relationship between pelvic inclination and pressure ulcers, Miki et al. pointed out that "the increase in pelvic inclination angle increases sacral sitting and increases pressure ulcer risk" [28]. The results from this study showed that the A-cushion and the self-made cushion tended to be highly effective and the effectiveness depended on the condition of the subject. It may be possible to develop technology that can avoid pressure ulcer risk by using different cushions. To that end, it is necessary to increase the number of target subjects in the future. In the comparison of contact areas at the time of the comfort survey, although values for the A-cushion and self-made cushion were high, there was no significant difference among the groups with cushions.

When comparing functional measurements, there was a significant difference between the A-cushion and the self-made cushion. Kanbayashi et al. investigated the extent to which the material properties of the cushion affect anterior reach in healthy subjects. They concluded that the A-cushion is excellent in terms of pressure dispersion but not advantageous in the reach function.

However, according to results of the present study, the A-cushion was more effective than the F-cushion and the self-made cushion was similar to the A-cushion. In elderly individuals without lower limb function, muscle strength in the trunk/lower limb is insufficient. As a result, the buttock can be made more stable using a cushion that conforms to the anatomical shape. As such, functionality is believed to have increased with the appropriate cushion.

In other words, results suggested that the A-cushion and F-cushion in the elderly were more stable and effective for function by reproducing the shape of the buttocks. Regarding the center-of-gravity movement, no significant difference was found with or without a cushion in both the front and rear and in the left and right directions. This means that center-of-gravity movement with body movement is constant regardless of the presence of a cushion.

The various effects of multi-faceted sheeting performed by the therapist may have influenced the comfort and functionality of wheelchair sitting. On one hand, although function itself does not differ greatly depending on the cushion, the A-cushion is expensive and requires regular air conditioning. On the other hand, the self-made cushion uses an inexpensive urethane material and has the advantage that maintenance is required only once per year.

From the perspective of pressure ulcer risk, the A-cushion is made of plastic and deteriorates in wet environments, whereas the self-made cushion uses a reticulated cushion material [29] that is highly maintainable in addition to urethane. The self-made cushion has other advantages over the A-cushion in preventing pressure ulcer(s) and healing eczema and infections.

Because "sheeting" has been included in the rehabilitation fee for each disease 
in 2017 and can be calculated [30], the custom fabrication of cushions for rehabilitation has become popular. In the future, we anticipate the development of cushions that can enhance the functions of the target individual by taking into account sling seat deflection and the shape of the buttocks for diaper users when fabricating their own cushions.

\section{Conflicts of Interest}

The authors declare no conflicts of interest regarding the publication of this paper.

\section{References}

[1] McClenaghan, B.A. (1989) Sitting Stability of Selected Subjects with Cerebral Palsy. Clinical Biomechanics, 4, 213-216. https://doi.org/10.1016/0268-0033(89)90005-3

[2] Reid, D.T., Sochaniwskyj, A. and Milner, M. (1991) An Investigation of Postural Sway in Sitting of Normal Children and Children with Neurological Disorders. Physical \& Occupational Therapy in Pediatrics, 11, 19-35. https://doi.org/10.1080/J006v11n01_02

[3] Sochaniwskyj, A., Koheil, R., Bablich, K., Milner, M. and Lotto, W. (1991) Dynamic Monitoring of Sitting Posture for Children with Spastic Cerebral Palsy. Clinical Biomechanics, 6, 161-167. https://doi.org/10.1016/0268-0033(91)90028-O

[4] Dursun, E., Hamamci, N., Donmez, S., Tuzunalp, O. and Cakci, A. (1996) Angular Biofeedback Device for Sitting Balance of Stroke Patients. Stroke, 8, 1354-1357. https://doi.org/10.1161/01.STR.27.8.1354

[5] Chari, V.R. and Kirby, R.L. (1986) Lower Limb Influence on Sitting Balance While Reaching Forward. Archives of Physical Medicine and Rehabilitation, 67, 730-733. https://doi.org/10.1016/0003-9993(86)90005-5

[6] Bendix, T., Jessen, F. and Krohn, L. (1988) Biomechanics of Forward-Reaching Movements While Sitting on Fixed Forward or Backward-Inclining or Tiltable Seats. Spine, 13, 193-196. https://doi.org/10.1097/00007632-198802000-00011

[7] Son, K., Miller, J.A.A. and Schultz, A.B. (1988) The Mechanical Role of the Trunk and Lower Extremities in a Seated Weight-Moving Task in the Sagittal Plane. Journal of Biomechanical Engineering, 110, 97-103. https://doi.org/10.1115/1.3108424

[8] Moore, S. and Brunt, D. (1991) Effects of Trunk Support and Target Distance on Postural Adjustments Prior to a Rapid Reaching Task by Seated Subjects. Archives of Physical Medicine and Rehabilitation, 72, 638-641. https://doi.org/10.1093/ptj/72.5.335

[9] Curtis, K.A., Kindlin, C.M., Reich, K.M. and White, D.E. (1995) Functional Reach in Wheelchair Users: The Effects of Trunk and Lower Extremity Stabilization. Archives of Physical Medicine and Rehabilitation, 76, 360-367. https://doi.org/10.1016/S0003-9993(95)80662-8

[10] Seelen, H.A.M., Potten, Y.J.M., Huson, A., Spaans, F. and Reulen, J.P.H. (1997) Impaired Balance Control in Paraplegic Subjects. Journal of Electromyography and Kinesiology, 7, 149-160. https://doi.org/10.1016/S1050-6411(97)88884-0

[11] Letts, M., Rang, M. and Tredwell, S. (1985) Seating the Disabled Atlas of Orthotics. In: American Academy of Orthopaedic Surgeons, 2nd Edition, the C. V. Mosby Co., St. Louis, 440-444.

[12] Collins, F. (2002) Use of Pressure Reducing Seats and Cushions in a Community 
Setting. Journal of Community Nursing, 7, 15-22.

https://doi.org/10.12968/bjen.2002.7.1.9439

[13] Riley, P.O., Benda, B.J., Gill-Body, K.M. and Krebs, D.E. (1995) Phase Plane Analysis of Stability in Quiet Standing. Journal of Rehabilitation Research \& Develop ment, 32, 227-235.

[14] Dean, C.M. and Shepherd, R.B. (1997) Task-Related Training Improves Performance of Seated Reaching Tasks after Stroke. Stroke, 28, 722-728. https://doi.org/10.1161/01.STR.28.4.722

[15] Hidetoshi, N., Emiko, D., Suguru, A., Satomi, K. and Tetsuya, U. (2018) Effects of Different Seat Mechanism on Body Pressure Dispersibility, Driveability, Dynamic Balance Ability in Care Facility User. Bulletin of Osaka Kawasaki Rehabilitation University, 12, 47-53.

[16] Tadamitsu, M., Atsushi, M., Yasushi, K., Miki, T., Yasuaki, K. and Osamu, N. (2018) Effect of Changes in Pelvic Tilt on Center of Sitting Pressure Displacement in the Lateral Reach Test and Its Relationship with Trunk Function. Physiotherapy Science, 32, 899-903. https://doi.org/10.1589/rika.32.899

[17] Nahoko, K. and Kazumasa, Y. (2015) The Influence of the Distance to the Seat Surface Pressure Center on the Lateral Reach Distance in the End-Sitting Position at Different Pelvic Limb Positions and the Relationship with Trunk Function. Bulletin of Aichi Medical College for Physical and Occupational Therapy, 6, 73-79.

[18] Tomoko, K., Syuichi, S., Hideki, S. and Kouji, Y. (2007) Effect of Seat Cushion Materials on Dynamic Stability in Sitting during a Forward Reaching Task. Aomori Health University Magazine, 8, 37-44.

[19] Takashi, K. (2006) Elderly Seating. Physiotherapy Hyogo, 12, 29-36.

[20] Hedeki, H. and Kiyomi, K. (2014) Seating for Persons with Disabilities. Miwa-Shoten, Tokyo, 48-49.

[21] Matsubayashi, K., Kimura, S., Iwasaki, T., Okumiya, K., Hamada, T., Fujisawa, M., Takeuchi, K., Kawamoto, T. and Ozawa, T. (1992) Application of Visual Analogue Scale of Happiness to Elderly Himalayan Highlanders. Japanese Journal of Geriatrics, 29, 811-816. https://doi.org/10.3143/geriatrics.29.811

[22] Crane, B., Kemmoku, T., Handa and Hirose, T. (2009) Measurement of Seated Posture and Wheelchair Seating to ISO06840-1. 25th International Seating Symposium, Orlando, 155-156.

[23] Masafumi, A., Noriyasu, K. and Taizo, S. (2007) Reliability and Validity of a Multi-Directional Reach Test for Patients with Stroke. The Journal of Japanese Physical Therapy, 34, 279-285.

[24] Ministry of Health, Labour and Welfare (2001) "Wheelchairs" and "Chairs" to Eliminate Physical Restraints. Guide to Zero Body Restraints. Welfare Local Government Unit, Tokyo, 30-36.

[25] Takashi, H. and Hideki, H. (2010) Development of Seated Posture Measurement Software Which Enables to Apply ISO 16840-1 Standard in a Clinical Setting. The Journal of Japanese Society for Wellbeing Science and Assistive Technology, 10, 27-35.

[26] Bengt, E. (2003) Ergomomic Seating. Posturalis Books, Strängnäs, 67-70.

[27] Takahiro, I. (2013) Usefulness of Modular Wheelchair from the Viewpoint of Body Pressure Dispersion Ability. Home Health Care for the People with Intractable Diseases, 19, 57-59.

[28] Taro, M., Katuro, F. and Tadasi, M. (2013) Relationship of Seated Posture and Force 
on the Gluteal Region. Journal of Japanese Society of Prosthetic, 29, 168-174.

[29] Taishi, E., Osamu, N., Masahiro, M., Takeshi, T. and Kei, K. (2016) Effects of Different Types of Cushions in $30^{\circ}$ Lateral Decubitus Position on the Moist Environment in the Contact Area between the Cushion and the User's Body. Journal of Professional Rehabilitation Study Group, 15, 10-14.

[30] Takashi, K. (2019) Future Deployment of Seating Technology. Journal of Japanese Society of Prosthetic, 35, 166-172. 